\title{
Liminal Space in J. G. Ballard's Concrete Island
}

\section{ABSTRACT}

This article explores the way in which surrealist techniques and assumptions underpin spatial representations in Ballard's Concrete Island. With much of Ballard's fiction using spatiality as an ideologically charged instrument to articulate a critique that underpins postcapitalist culture, it seems important to focus on exactly the kind of spaces that he creates. This paper will investigate the means by which spatiality is conceptualized in Ballard's fiction, with special emphasis on places situated on the borders between realism and fantasy. Ballard's spaces, often positioned on the edgelands of cities or centers of civilization, can be aligned with the surrealist project as presented not only by the Situationalist International, but of psychogeographical discourse in general. What the various Ballardian spaces-motorways, airports, high-rises, deserts, shopping malls, suburbs-have in common is a sense of existing outside stable definitions or what, following Marc Augé, we would call nonplaces, which by their definition are disconnected from a globalized image society, thus generating a revolutionary idea of freedom. As these places exist outside the cognitive map we impose on our environment, they present a potentially liberating force that resonates in Ballard's fiction.

Keywords: Ballard, surrealism, psychogeography, spatiality. 
Though James Graham Ballard is perhaps best known as a representative of New Wave sf, his literary debt to surrealism and modernist techniques of estrangement has only recently become the subject of critical attention. ${ }^{1}$ Championed by New Worlds editor, Michael Moorcock, and praised by Judith Merril for elevating science fiction to a more sophisticated literary genre, Ballard successfully infused ambiguity and allusiveness to a literary genre which had defiantly resisted such literary pursuits. Influences of surrealism can be seen in most of his works, especially in the imagery, ekphrastic allusions to surrealist paintings, and general rejection of scientific rationality in favor of speculative imagination, psychoanalytical references, and a rebellious 1960s affirmation of the transgressive. But it is the concept of liminality that constitutes an integral point of intersection between surrealism and Ballard's fiction. The way liminal spaces function as a destabilizing agent, challenging power relations and subverting established social constructs link them to Andre Breton's surrealist project and later to Guy Debord's Situationist International movement. These operations, as well as their relevant contexts will be exemplified with reference to J. G. Ballard's Concrete Island, a work in which the agency of spatial liminality showcases the effects of surrealist estrangement.

Space, whether it be monstrous, consuming or uncanny, figures as the primary agent in many of Ballard's novels and short stories. One needs only to take a short glance at the titles to see how central spaces and places are to his imagination: High-Rise, The Drowned World, The Crystal World, Concrete Island, Rushing to Paradise, "Enormous Space," etc. In these texts the characters are often relegated to a secondary role, their reactions to their environments observed in much the same way as an animal behaviorist would examine animals in a laboratory-their behavior triggered and later unleashed by the subtly repressive conveniences provided by modern technology and urban planning, or by sudden alterations to habitual everyday routine. This primary role afforded to the environment is enabled by the corollary passivity of the characters, a characteristic of many of Ballard's novels and shorts stories, rendering the subject especially responsive to the effects of their environment. With this in mind, we can see that liminal spaces are a particularly productive environment. Due to their already ambiguous status as spaces, liminal spaces defy clear categorization, as they are always in flux. As such,

1 Both Roger Luckhurst in The Angle Between Two Walls: The Fiction of J. G. Ballard and Andrzej Gasiorek in J. G. Ballard draw attention to the presence of surrealism in Ballard's work, but Jeanette Baxter's J. G. Ballard's Surrealist Imagination is the only book-length study of the various references and inspirations Ballard's work maintains with the surrealist tradition. 
borderlands do not belong to any definable space, they are in-between and thus somehow released from the structural authority of a polis, nation-state or any governing authority. This spatial indeterminacy affords the subjects freedom to redefine themselves outside the dictates and symbolic determinations governing their social spaces; however, what Ballard's novels attempt to explore are the psychological effects of inhabiting a borderland for an extended period of time.

The spaces that occupy many of Ballard's novels and short stories-at least the ones that live up to the adjective "Ballardian"-bring to mind a postcapitalist dystopia characterized by bleak, manmade landscapes, oftentimes occupying a borderland of sorts, a liminal zone where identity and meaning are brought into question. Ballard's topographies are always suspended in an interstitial zone, either geographically between definable zones (rural, urban) or temporally between the defunct utopian modernist projects and the unreal, unsustainable present. For example, the titular high-rise from his 1975 novel is situated with London in receding view but nonetheless separated from the monotonous malaise it represents; his titular concrete island from his 1974 novel is always in clear view of the surrounding motorways, all the while remaining anonymous and, in a certain topographical sense, absent. There is an almost revolutionary impulse in these spaces which remain outside the cultural and social purview; at least this is the psychogeographical perspective that Ballard seems to draw on in his representations of subjects and subjectivities disintegrating under the pressure of this spatial indeterminacy. ${ }^{2}$

These blank spaces, unresolvable in their definition as place and situated beyond the symbolic representations of topographical mapping, provide Ballard with a liminal environment where the subject of inquiry shifts from exterior spaces to "inner spaces." ${ }^{3}$ It is now subjectivity and the psychological landscape that become the focus as a result of the liminal nature of the physical environment, and it is at this juncture that

2 Such blank spaces within the urban landscape were seen as the prized destinations of psychogeographers, writers who take their cue from the Situationist of the 1960s, a movement influenced by Guy Debord's celebrated Society of Spectacle. This tradition is upheld by Iain Sinclair and Will Self, both of whom have paid homage to Ballard, naming him as an inspiration and one of the most important British authors of the $20^{\text {th }}$ century.

3 In 1962 Ballard as a guest editor of New Worlds published "Which Way to Inner Space," expressing his frustrations with the staid conventions of sf, a genre which he considered aptly suited, but underutilized, to represent the changing conditions of modern life. He thus redefined the goals of New Wave sf in contrast to the Golden Age of sf represented by Hugo Gernsback, suggesting a shift in focus from outer space to inner space. 
Surrealism can be seen as providing Ballard with a vibrant depository of techniques and images to transcend the conventions typically associated with mainstream sf.

A fine example of such a liminal space can be found in Ballard's Concrete Island (1974), which is part of the urban disaster trilogy consisting also of Crash (1973) and High-Rise (1975). Whereas Crash and High-Rise deal with a more claustrophobic setting, addressing the effects of modern technology and architectural environments, Concrete Island opens itself up to a more agoraphobic space. ${ }^{4}$ The protagonist of Concrete Island is a 35-year-old architect, Robert Maitland, who one day while homebound on the exit lane of the Westway interchange in west London veers off, crashing his Jaguar through the ramps onto a deserted wasteland beneath and between the motorways. This island is described as "a small traffic island, some two hundred yards long and triangular in shape, that lay in the waste ground between three converging motorway routes" (Ballard 11). This space is a forgotten by-product of urban development, a negative space that has resisted incorporation into the homogenized space of the urban environment. After a series of predictable but ultimately futile escape attempts, he begins to explore this land in hopes of mapping it, finding help, food and shelter, but the landscape is so overgrown that Maitland is unable to find his bearings. Ultimately, the island, as a liminal zone, is unknowable, resistant to cognitive mapping of any kind. Eventually, he comes across two socially outcast inhabitants, Jane Sheppard and Proctor, a street-smart young woman and a mentally disabled ex-circus performer, who take him in, but whether as a patient, hostage, or guest is never certain. Incapacitated by his injuries and by days of having to fend for himself without food and shelter, he is at first at the mercy of his hosts. Eventually, however, the time spent on the island gradually removes the vestiges of his habitual bourgeois behavior and Maitland, instead of struggling to rescue himself, decides to exert his dominion on the island.

Ballard presents Maitland as a typical example of an urban dweller, not only by means of his profession and demeanor, but also because of the deep-seated alienation that distances him from other people. George Simmel in "Metropolis and Mental Life," in discussing the various psychological conditions resulting from urban life, identifies alienation as the natural consequence of this new spatial arrangement characterized by multiplicity, heterogeneity and intensified tempo, which ultimately lead to the blasé attitude characterizing urban dwellers. This distance is seen as

4 Incidentally, both of these psychopathologies were diagnosed at the beginning of the $20^{\text {th }}$ century and applied exclusively to urban environments. Cf. Anthony Vidler's Warped Space: Art, Architecture and Anxiety in Modern Culture. 
a necessary defense mechanism against the barrage of impulses constantly assaulting the senses. Thus, appropriately, Ballard provides the readers with a backstory in which Maitland's private life is defined by the safe distances he was able to establish between himself and the surrounding social environment. In fact, he succeeded at separating himself from his wife and coworkers to the extent that his absence was not even noticed and, as a result, no search party was ever launched. This is a character whose emotional isolationism likens him to the kind of detached heroes epitomized in Herman Melville's Bartleby or Robert Musil's Man without Qualities. In both cases the capitalist urban backdrop is evoked as an important factor in the alienation of the characters.

The question that runs through the story hinges on the psychogeographical relation of this space to Maitland: how the one affects the other. Especially provocative is the depiction of his gradually shifting behavior - at a certain point he is no longer concerned about his life beyond the embankments and is no longer desperate to leave; instead, he passively resigns himself to his new situation and embraces this new environment as his own. Ballard here creates a mild version of a cozy apocalypse, where repressed desires and fantasies of isolation and solitude are fulfilled. There is a haunting effect that this space exerts on Maitland, as it drains his will and deprives him of his previous identity - that of a well-mannered, upperclass architect, who now proclaims that his goal is to exert dominion over his new territory, a theme that coincides with the story's two most important intertexts-Robinson Crusoe and The Tempest.

Ballard's inclusion into psychogeographical literature also rests on these moments of psychological responses to spatial environments, responses which merge the mind with the environment to the extent that they become almost inseparable. For example, Concrete Island, according to Andrzej Gasiorek, is "an extension of Maitland's psyche, the external manifestation of the unresolved inner conflicts he projects onto it, and on the other hand, it represents the physical challenge of survival” (114). Descriptions of the landscape become interchangeable with descriptions of Maitland as the following quote makes clear:

Comparing it with the motorway system, he saw that it was far older than the surviving terrain, as if this triangular patch of waste ground had survived by the exercise of unique guile and persistence, and would continue to survive, unknown and disregarded, long after the motorways had collapsed into dust. (Ballard 69)

It is a Ballardian trademark to anthropomorphize inanimate objects such as buildings, as was the case in High-Rise, or the natural environment, 
as is the case in Concrete Island, which is why it is crucial to understand the specific nature of the kind of environment Ballard is presenting, as these spaces are the prime actors in these narratives, at times exerting more agency than the characters themselves.

In many of the commentaries about Concrete Island, Marc Augés notion of non-spaces has been utilized as a theoretical framework to present the heterotopic space represented in the novel in its ideological relevance as a postmodern, postcapitalist, posthistorical space, where the excess of events and signifiers disintegrate organically social spaces. With the pace of globalization and the effects of what David Harvey terms the "space-time compression" individuals become consigned to the role of inactive witnesses, their identity no longer resulting from organic social conditions, but from what Augé calls the "solitary contractuality" of non-places. The most common examples of these non-places which Augé sees proliferating the postmodern, postcapitalist landscapes are airport terminals, supermarkets, motroways, and hotel chains or just about any place where upon entering a person "is relieved of his usual determinants. He becomes no more than what he does or experiences in the role of passenger, customer or driver" (Augé 103). In all these cases we are dealing with either places of transition from, or with focalized places of, consumerism (or both as with the duty-free area in airports). Augé has been criticized for not only misreading de Certeau whose conception of space and place provides a starting point for his own analysis but also because of a pervading sense of nostalgia for "some mystical, pastoral type of collective existence" (Buchanan 62). I think it is important not to fall into this line of argument in analyzing Ballard, i.e. not seeing this descent as a primitivist revival of experience, which incidentally would mean reading against Ballard's own intentions, as evidenced in the preface to Concrete Island, where he refers to "the challenge of returning to our more primitive natures, stripped of the self-respect and the mental support systems with which civilization has equipped us" (qtd. in Gasiorek 114).

Indeed, on one level, Concrete Island may be construed, following Ballard's lead, as a reactionary fantasy about finding your authentic self in an acultural, pastoral type setting, but what I believe is more interesting is how this narrative is inscribed into a greater narrative of Surrealism, which is based in part on dismantling and reconfiguring our conception of reality. Ballard utilizes surrealistic motifs and techniques for the purpose of presenting a spatial construct which works in tandem with the psychological restructuring of the protagonists himself. This psychogeographical

5 See Harvey (260-307). 
element of the narrative serves a dual purpose: 1) in unifying spatiality with psychology, Ballard is externalizing latent and repressed trauma (which would be in accord with his statements about "inner space" in New Worlds) and 2) because the concrete island is an interstitial borderland, Ballard is, at the same time, presenting a liminal experience. The two interlacing points mentioned above (externalization of trauma and presentation of liminal experience) reveal the hidden political project of Surrealism, which was to subvert and destabilize the established societal norms and protocols; such a project, I believe, informs Ballard's texts and goes beyond the clear-cut classification of this zone as a non-place.

To better develop the mechanism of this project, it is helpful to elaborate on Freud's concept of the uncanny. If the uncanny is understood in its spatial dimension, then we see how architecture is coopted into the surrealist project of invoking the feeling of estrangement that is a necessary step towards this liminal experience. Surrealist painters such as Giorgio de Chirico and Rene Magritte aestheticized the experience of the uncanny by frustrating spatial mapping, eliminating codified cues and conventions that make space understandable. This other spatiality, or heterotopia, with which surrealists are concerned is what M. StoneRichards refers to as the dessaisissement de l'espace, "a spatiality marked by passage and transition-and where architectural metaphoricity encounters, comes with, the possibilities of defamiliarization and dislocation of space, ..." (255). This is what is translated as the undoing of space (255). The effect produced by this other spatiality is a feeling of disorientation and cognitive confusion, not unlike the disorientation Freud discusses in "The Uncanny," where

caught in a mist perhaps, one has lost one's way in a mountain forest, every attempt to find the marked or familiar path may bring one back again and again to one and the same spot, which one can identify by some particular landmark. (237)

Martin Heidegger's account of place in Sein und Zeit calls this experience Ent-fernung, or deseverence, a condition which opens the possibility for an encounter with alterity by diminishing the distance between an entity and Dasein. This experience of self-awareness and disalienation is precisely what the situationists hoped to evoke by means of their intoxicated drifts through the streets of Paris, not unlike those described by Breton in Nadja (1928). Such an experience of disorientation was meant to jolt the subject from his routine-oriented consumerist existence experienced in urban settings, where rationalized space contributes to the sense of isolation. This is so, because " $[\mathrm{t}]$ he voided 
spaces of modernity are frequently reductivist, abstracted, hygienic, homogenized, and continuous-designed to suppress the individuated, coarse, theatrical, perverse, or the traumatic" (Mical 6).

What then accounts for the uncanny nature of this patch of land on which Maitland is marooned? Certainly, there is the intellectual and physical sense of uncertainty, which for Ernst Jentsch was a defining factor of the uncanny, ${ }^{6}$ pervading Maitland's attempts to come to terms with his new environment; this uncertainty is further heightened by a haunting sense of familiarity which effectively undercuts his attempts to seek escape. The mixture of strangeness and familiarity defines this uncanny psychogeography and places Maitland in a position of utter confusion. His explorations of the island uncover a vast historical topography that has been literally concealed by concrete; there are ruins of an old Edwardian house, a bomb shelter, and he goes on to identify "[a]round the ruin of a former pay-box ... the ground-plan of a postwar cinema, a narrow single-storey flea-pit built from cement blocks and galvanized iron. Ten feet away, partly screened by a bank of nettles, steps ran down the basement" (Ballard 69). These revelations force us to reevaluate our initial impressions of this space as a modern wasteland without a history of its own must. What initially appeared as a non-place is in fact laden with ghostly traces of an earlier urban topography that has not been fully erased by rampant modernization. It is, therefore, telling that the spatial production of capitalist modernity should take place on the ruins of a past that is abandoned and suppressed. This aspect of the past encroaching on the concrete island is yet another reason why Marc Augés non-place may not be the appropriate term to describe this particular space, as non-places are manifestly ahistorical and acultural, whereas here we are dealing with a spectral historicity that further aligns this space with the uncanny.

What is perhaps the most important turn in this story is that eventually Maitland begins to feel at home in this once hostile environment; he effectively domesticates this space, divesting it of the uncanniness that had initially defined it, which leads us to the following related question: what then does it mean to make a home in the borderlands, in a place that eludes all definitions? Heidegger in "The Origin of the Work of Art" sees the home as the locus of the uncanny:

We believe we are at home in the immediate circle of beings. That which is familiar, reliable, ordinary. Nevertheless, the clearing is pervaded by a constant concealment in the double form of refusal and

6 Cf. Jentsch (7-16). 
dissembling. At bottom the ordinary is not ordinary; it is extraordinary, uncanny. (54)

This quote describes the obverse situation of how the uncanny is usually concealed from our view by the force of habit, a habitual familiarity with which we endow our environment with the illusion of homeliness. Commenting on the effect of habit on memory, Beckett remarked in his essay on Proust that

[t] he laws of memory are subject to the more general laws of habit. Habit is a compromise effected between the individual and his environment, or between the individual and his own organic eccentricities, the guarantee of a dull inviolability, the lightening-conductor of his existence. Habit is the ballast that chains the dog to his vomit. (19)

This evocative image presents Beckett's rejection of habit, seeing in it a threat to creativity (his "organic eccentricities"), at the same time holding us hostage to the mundane and unremarkable aspects of our existence and also grounding us in existence much like a lightning-conductor grounds the uncontrollable force of lightning. Whereas the Modernist text would locate habit-breaking moments of authenticity in such transcendent moments as Proust's involuntary memory or Joyce's epiphanies, Ballard makes use of deseverence as a step towards the reappropriation of spatiality through a radical experience of place.

In conclusion, it is clear that, though Ballard is not typically considered a Surrealist writer, he employed many of the techniques and aesthetic principles of Surrealism; most importantly, the landscapes he painted in his works recall the foreboding spaces we find in de Chirico or Max Ernst. It is not just in these spaces but by means of these spaces that the principle themes of Ballard's work are played out. And because these spaces are situated outside the rational, thus offering a contradistinction to the modernity project, they continue the surrealist project of aesthetically and ideologically rupturing established boundaries, subverting socially constructed notions, all in the name of yielding a more direct interaction with the spatial environment. Ballardian borderlands present us with a fertile means of delving into the ambiguities of liminal spaces. What makes liminality a potent theoretical notion is its ability to recontextualize the ideological flux, unstable meanings, fluctuating certainties, which characterize postmodern thought, especially in relation to identity politics. In the case of Concrete Island this borderland as a liminal space affects a ritualistic passage into an apocalyptic state of liberation, the kind that Ballard repeatedly presents as an antithesis to the modern utopian fantasy. 


\section{Works CiTED}

Augé, Marc. Non-Places: Introduction to an Antbropology of Supermodernity. Trans. Jon Howe. London: Verso, 1995. Print.

Ballard, J. G. Concrete Island. London: Fourth Estate, 2011. Print.

Baxter, Jeannette. J. G. Ballard's Surrealist Imagination: Spectacular Authorship. Farnham: Ashgate, 2009. Print.

Beckett, Samuel. Proust and Three Dialogues with Georges Duthuit. London: John Calder, 1965. Print.

Buchanan, Ian. Michel de Certeau: Cultural Theorist. London: Sage, 2000. Print.

Freud, Sigmund. "The Uncanny." The Standard Edition of the Complete Psychological Works of Sigmund Freud. Volume XVII. Trans. James Strachey. London: Hogarth, 1955. 217-52. Print.

Gasiorek, Andrzej. J. G. Ballard. Contemporary British Novelists. Manchester: Manchester UP, 2004. Print.

Harvey, David. The Condition of Postmodernity: An Enquiry into the Origins of Cultural Change. Oxford: Blackwell, 1991. Print.

Heidegger, Martin. "The Origin of the Work of Art." Poetry, Language, Thought. Trans. Albert Hofstadter. New York: Haper and Row, 1971. 15-87. Print.

Jentsch, Ernst. "On the Psychology of the Uncanny." Trans. Roy Sellars, Angelaki. A New Journal in Philosophy, Literature, and the Social Sciences 2.1 (1996): 7-16. Print.

Luckhurst, Roger. The Angle Between Two Walls: The Fiction of J. G. Ballard. Liverpool: Liverpool UP, 1997. Print.

Mical, Thomas. Introduction. Surrealism and Architecture. Ed. Thomas Mical. London: Routledge, 2005. 1-10. Print.

Simmel, Georg. "Metropolis and Mental Life." Classical and Contemporary Sociological Theory: Text and Readings. Ed. Scott Appelrouth and Laura Desfor Edles. Los Angeles: Pine Forge/Sage, 2008. 265-73. Print.

Stone-Richards, M. "Latencies and Imago: Blanchot and the Shadow City of Surrealism." Surrealism and Architecture. Ed. Thomas Mical. London: Routledge, 2005. 249-72. Print.

Vidler, Anthony. Warped Space: Art, Architecture, and Anxiety in Modern Culture. Massachusetts: MIT, 2000. Print.

Marcin Tereszewski is Assistant Professor at the University of Wrocław, Poland, where he specializes in modern British fiction and literary theory. He is the author of The Aesthetics of Failure: Inexpressibility in Samuel Beckett's Fiction (Cambridge Scholars, 2013). His 
current research interests include an examination of psychogeographical aspects of dystopian fiction, particularly in relation to J. G. Ballard's fiction and architecture.

mtereszewski@yahoo.com 